\title{
The Random Walk Model in the Pakistani Equity Market: An Examination
}

\begin{abstract}
FAZAL HUSAIN
This paper examines the validity of the Random Walk Model in the Pakistani equity market. The model, extensively tested in other equity markets, implies that past movements in a stock price are not helpful in predicting future prices of that stock. The model states that changes in stock prices are serially independent and conform to some probability distribution. Conventionally, the independence part is examined through Serial Correlation Test, whereas the distributional aspect is analysed through Frequency Distributions. Same techniques are applied in this paper on daily closing prices of 36 individual stocks, 8 sector indices, and a market index from January 1, 1989 to December 30, 1993.

The analysis indicates that the Random Walk Model is not valid in the Pakistani equity market as is the case in other emerging markets. The results show the presence of strong serial dependence in stock returns and indicate the slow adjustment of the market to new information. This points to the weaknesses of the market regarding the dissemination of pertinent information to potential investors, indicating that effective measures should be taken in this regard. The shape of the distribution reveals that stock returns in the Pakistani market, like in other equity markets, do not comply with the normal distribution, implying that theoretical models must be used with caution.
\end{abstract}

\section{INTRODUCTION}

The behaviour of stock prices has been a recurrent topic in the academic circles for a long time. In this context, financial researchers have developed various theories and models which have been tested empirically for different equity markets. Among such models is the Random Walk (RW) model, one of the earliest models proposed for stock price behaviour, which states that future stock prices can not be predicted on the basis of past price movements. To an investor, the model implies that investment strategies based on past information will not necessarily yield higher returns than a portfolio consisting of randomly picked stocks.

Fazal Husain is Research Economist at the Pakistan Institute of Development Economics, Islamabad.

Author's Note: This paper is based on my Ph.D. dissertation (Catholic University of America, 1996). I am grateful to my supervisors, Dr Jamshed Uppal, Dr Reza Saidi, and Dr Kevin Forbes, for their guidance during the study. I am also grateful to Dr Nasir Khilji, Dr Eatzaz Ahmed, and Mr Tariq Mahmood for their comments on an earlier draft of this paper. 
The model is considered to be valid in developed markets, particularly the U.S. capital market. Kendall (1953); Granger and Morgenstern (1963); Fama (1965); Dryden (1970); Solnik (1973), etc., are unable to statistically reject the RW hypothesis. In particular, Fama (1965), the most comprehensive study on the issue, claims to have found strong and voluminous evidence in favour of the RW hypothesis while analysing daily stock return behaviour in the New York stock exchange.

On the other hand, the evidence from developing markets, commonly known as emerging markets, casts doubts on the validity of the model in general. For example, Malaikah (1990) and Aybar (1992) find that RW hypothesis does not describe the stock returns behaviour in the capital markets of Saudi Arabia, Kuwait, and Turkey. This suggests that the application of RW hypothesis to other capital markets may provide useful insights regarding the validity of the hypothesis.

The purpose of this paper is to conduct such an exercise in the Pakistani equity market, which is one of the promising emerging markets identified by the International Finance Corporation (IFC). The market has been the subject of significant changes in recent years. Like other developing nations, Pakistan has also taken significant steps towards the development of its capital market. Measures have been taken for privatisation, economic liberalisation, relaxation of foreign exchange controls, and easing of regulations on repatriation of profits, investment, and operation of financial institutions.

The empirical studies of the behaviour of stock returns in the Pakistani equity market are few, for example, Khilji (1993, 1994); Uppal (1993); Ahmed (1995), etc. However, none of the studies specifically tests the RW hypothesis. Moreover, the lack of a sufficiently long time-series data and the use of broad indices limit the generality of their findings. This paper uses daily closing prices of individual stocks, adjusted for dividends, rights issues, etc., for a longer time-period to examine the RW model.

The paper is organised as follows. The next section overviews the Pakistani equity market. Section III describes the data sources, hypotheses, and methodology. Section IV reviews the studies on the emerging market and the Pakistani equity market and presents the empirical results of this study. The final section contains the summary and conclusions.

\section{THE PAKISTANI EQUITY MARKET}

\section{History}

The first and the main equity market, the Karachi Stock Exchange (KSE), came into existence on September 1947, which was later incorporated as a company limited by guarantee on March 1949. At that time it had 90 members and 5 listed companies with a paid-up capital of Rs 37 million.

Pakistan's economy made steady progress in the 1950s largely due to a healthy mix of private initiative and Government support. As a result, the stock market also 
made progress and listings rose to 81 companies by 1960, with a paid-up capital of above Rs 1.0 billion, while the market capitalisation was about Rs 1.9 billion. The economic progress continued in the 1960s, particularly in the first half of the decade the economy experienced remarkable growth. However, a war with India in 1965 and the socio-political unrest in the late 1960s affected the economy adversely. Nevertheless, the stock market continued to expand, and by 1970 the listings rose to 318 while market capitalisation increased to Rs 4.25 billion.

Although the 1970s started with the formation of another exchange, the Lahore Stock Exchange, which began functioning in May, 1971, the decade remained dismal in terms of the stock market due to adverse economic and political conditions. A separatist movement in the Eastern wing of the state of Pakistan caused another war with India in 1971 that resulted in the separation of the Eastern wing. Subsequently, a socialist government came into power and started nationalising large segments of industry, insurance, and banks. This policy discouraged the private business activities, and with it the stock market. A political movement against that government in the late 1970s resulted in its removal and the imposition of Martial Law. These political fluctuations in the country paralysed the investment atmosphere and proved fatal for the stock market. Overall, by 1980, the number of listed companies was 314, while the market capitalisation increased to Rs 6.36 billion.

The 1980s began with a policy of greater reliance on private enterprise. In the budget for the year 1985-86, significant measures were taken which improved the investment climate and restored the business confidence that had a favourable impact on stock market activity. As a result, by 1990 , listings rose to 487 while market capitalisation went up more than ten times, to Rs 61.9 billion, and annual turnover also rose nearly ten times, to 252.9 million shares, representing a traded value of Rs 5 billion.

The 1990s started with the measures taken to liberalise the economy, including the opening of the market to international investors and removal of constraints to repatriation of investment proceeds, etc. The market responded positively to these measures and by the end of 1991 listings rose to 542 while market capitalisation more than doubled to Rs 180.22 billion. Similarly, turnover and value traded increased twice to 12.6 percent and Rs 15.2 billion respectively. These developments were accompanied by inflow of foreign capital through the Commonwealth Equity Fund, the Pakistan Fund, and the Credit/Lyonnaisee Pakistan Growth Fund. Another important development was the creation of the third exchange in the country, the Islamabad Stock Exchange, that started operating on August 1992.

Although at present there are three stock exchanges operating in Pakistan, the KSE is the only truly active stock exchange and the bulk of trading takes place on its floor. Hence, this paper is based on the investigation of the behaviour of the KSE. 


\section{Regulations and Operations}

The Corporate Law Authority (CLA) regulates stock markets under the Securities and Exchange Ordinance (SEO), 1969. It is responsible not only for supervising stock exchanges and their members but also for licensing investment advisers, regulating prospectuses, and enforcing legislation pertaining to both companies and corporate securities. The responsibility to regulate the issue of capital is also performed by the CLA.

Initially, the membership of stock exchanges was confined to individuals and partnerships of individual members and their close relatives. Corporate memberships with a minimum paid up capital of Rs 20 million were allowed by the KSE through an amendment in its constitution in June, 1990. At present, there are about 32 corporate members.

In Pakistan, stock exchanges principally trade only in ordinary shares (common stocks). The shares are issued for a par value that is usually Rs 10 but can also be Rs 5, Rs 50, and Rs 100. The Companies Ordinance, 1984 does not permit any other type of equity. Hence, preference shares or debentures cannot be issued. Instead, companies issue Islamic instruments, Participation Term Certificates, Term Finance Certificates, and Modaraba Certificates.

The foreign investment, after the liberalisation measures taken by the Government in early 1991, does not require any government approval for purchasing the shares of a listed company or subscribing to public offerings of shares except in four security-related industries, for which the approval is required from the Investment Promotion Bureau (IPB), the foreign investment regulatory body.

\section{DATA SOURCES, HYPOTHESES, AND METHODOLOGY}

\section{Data Sources}

The data consist of 36 individual stocks, 8 sector indices, and a market index, covering the period from January 1, 1989 to December 30, 1993. Information on individual stocks regarding closing prices, volumes, dividends (cash \& stock), and rights issues was collected from the KSE, the CLA, and the Business Recorder (a daily newspaper).

The data on sector indices as well as the market index were obtained from the files of the State Bank of Pakistan, the central bank, that prepares and maintains these indices. The general market index, called the State Bank General Price Index, covers all the stocks listed on the exchange and, therefore, provides a complete representation of the market. 


\section{Methodology}

Following Fama (1965) and other subsequent studies, the return on a stock $\left(R_{t}\right)$ is defined as the first difference of the natural log of the stock prices $\left(P_{t}\right)$, that is,

$$
R_{t}=\ln P_{t}^{\prime}-\ln P_{t-1}
$$

Where $P_{t}^{\prime}$ is the price of a stock at time $t$ adjusted for capital changes, i.e., dividends, rights issues, etc.

\section{The Random Walk Model}

The RW model is based on two hypotheses: (i) successive values of returns in an individual stock are independent; and, (ii) stock returns conform to some probability distribution.

The first hypothesis deals with testing the existence of serial dependence in stock returns. The hypothesis has an important implication for an investor since he/she is interested to know whether there are dependencies in the series which can be used to increase the expected profits. The hypothesis is generally tested through the Serial Correlation Test, which is a parametric test that measures the relationship between the value of a random variable at time $t$, and its value $k$ period earlier, that is,

$$
r_{k}=\frac{\operatorname{Cov}\left(R_{t}, R_{t-k}\right)}{\operatorname{Var}\left(R_{t}\right)}
$$

Where $R_{t}$ is the return of a stock at time $t$. The standard error of $r_{k}$ is:

$$
S E\left(r_{k}\right)=\sqrt{\frac{1}{n-k}}
$$

Significant coefficients imply serial dependence where the significance of a coefficient is judged by its $t$-value. In addition, the signs of serial coefficients have important implications in the capital market. Positive signs reflect slow adjustment of stock prices to new information, insider information, etc., whereas negative serial correlation may be induced by thin market with wide fluctuations in prices about the intrinsic value.

Besides testing the individual coefficients, the joint hypothesis that all the correlation coefficients up to lag $k$ are zero is tested by the Ljung-Box $Q(k)$ statistic, computed as:

$$
Q(K)=n(n+2) \sum_{k=1}^{k} \frac{r_{k}^{2}}{n-i}
$$


Which has a chi square distribution with $k$ degrees of freedom.

The second hypothesis deals with the distribution of stock returns, which is an important issue both for investors and researchers. To an investor, it is important in determining the riskiness of investments in common stocks, i.e., he/she is interested in knowing the probability of gains or losses. On the other hand, it provides descriptive information concerning the nature of the process generating returns. In addition, understanding the returns distribution is crucial for the development and application of theoretical models.

However, there is a lack of consensus among researchers regarding the form of distribution of stock returns. Earlier studies assumed the distribution to be normal, but Mandelbrot (1963) and Fama (1965) show that the normality assumption is not compatible with empirical observations. In fact, the distribution observed empirically is leptokurtic that has fatter tails and a higher peak than normal. Whereas, there is a general agreement that the distribution of stock returns is leptokurtic, there is no agreement on the form of the distribution that can explain these leptokurtoses observed consistently in empirical studies. Due to this disagreement most of the studies that tested the RW model restricted their analysis to testing for the conformity of stock returns to normal distribution.

The conventional way of analysing the distribution of stock returns is to construct frequency distributions for stocks and compare them with that of the normal distribution. The excess of relative frequency in the centre indicates higher peaks. Similarly, the excess of relative frequency in the tails implies fatter tails. This measure provides a direct comparison of observed distribution with normal distribution and shows the degree of deviations of observed distribution from normality.

\section{EMPIRICAL EVIDENCE}

\section{Evidence from Other Emerging Markets}

It would be useful to look at the studies conducted in other emerging markets. This will help to compare the results of this study with those found in other markets.

Errunza and Losq (1985) investigate the behaviour of stock prices for a group of 10 emerging markets. ${ }^{1}$ Using monthly return series for 191 securities, they find the probability distribution of stock returns to be lognormal with some securities exhibiting non-stationary variances. The independence hypothesis is investigated by applying the serial correlation test that shows small and generally insignificant correlation coefficients, and, thus, supports the hypothesis.

Laurence (1986) examines stock price behaviour in Malaysia and Singapore. Daily closing prices for 16 stocks from Malaysia and 24 stocks from Singapore are

${ }^{1}$ The countries studied were Argentina, Brazil, Chile, Greece, India, Jordan, Korea, Mexico, Thailand, and Zimbabwe 
selected for the analysis. The results show slight deviations from the RW hypothesis on the two exchanges. The mean absolute serial coefficients for Malaysia and Singapore are 0.041 and 0.078 respectively. The distribution of returns over time is found to be leptokurtic.

Malaikah (1990) examines the RW hypothesis in the capital markets of Kuwait and Saudi Arabia. Using daily data on 35 Saudi stocks and 36 Kuwaiti stocks, the author applies the serial correlation and runs a test to examine the nature and extent of serial dependence. The mean lag one autocorrelation for Kuwaiti stocks is found to be 0.053 , with 36 percent of the stocks having statistically significant coefficients. In contrast, all 35 Saudi stocks are found to exhibit negative and statistically significant autocorrelation, with mean coefficient equal to -0.471 , which is opposite in sign and huge in magnitude as compared with autocorrelation coefficients reported in other studies.

Aybar (1992) studies the characteristics of the Istanbul Stock Exchange using weekly and daily data. Aybar finds the distribution of stock returns as departing from normal distribution. The results also indicate that Turkish equity market returns exhibit significant serial dependence both at daily and weekly intervals, and that no evidence is found of changes in serial dependence over time.

In summary, empirical evidence shows that stock returns in emerging markets do not comply with normal distribution. Leptokurtic distributions (with fatter tails and higher peaks relative to normal) found in these studies indicate departures from normality. Regarding serial dependence in stock returns, the RW model does not seem to be valid, in general, in emerging markets.

\section{Studies of the Pakistani Equity Market}

There are a few studies available which have examined stock returns behaviour in the Pakistani equity market.

Khilji (1993) investigates the time-series behaviour of stock returns in Pakistan using monthly indices. He finds the distribution of stock returns to be non-normal, generally positively skewed, and leptokurtic. Linear dependence is also observed for some indices. Using an error-correcting, first-order autoregressive model, and employing the Kalman Filter technique, the author attempts to determine the timevarying behaviour of monthly expected returns and finds expected returns to be constant and equal to long-term expected monthly return. However, as pointed out by the author, this is a surprising result in the context of a developing economy and needs further investigation by using weekly or daily data.

Uppal (1993) examines the relationship between stock returns in the Pakistani equity market and international equity markets. Using monthly indices for Pakistan, USA, UK, Japan, India, Australia, and Korea, the author uses the GARCH(p,q) 
technique to investigate the spillover effects in mean stock return and volatility of these markets on Pakistani market. He finds GARCH(1,1) to be an adequate representation of monthly stock returns in these markets. Regarding the spillover effects of foreign markets on Pakistani market, the author finds that volatility in Japan and Korea seems to have affected the Pakistani market in recent years.

Khilji (1994) investigates whether stock returns in Pakistan are characterised by non-linear dependence, using the test developed by Brock, Dechert, and Scheinkman (BDS). Using weekly indices, BDS tests are conducted on both returns and residuals from an autoregressive model. Strong non-linear dependence is found in six of the eleven indices. As mentioned by the author, this non-linear dependence could result from a non-linear deterministic system or a non-linear stochastic system. In order to distinguish between the two, the author suggests the use of non-linear stochastic models like GARCH to estimate the returns.

Jun and Uppal (1994) examine the characteristics of the Karachi Stock Exchange using the monthly IFC indices as well as monthly stock prices for 20 companies. The results show the distribution of stock returns to be non-normal. The analysis of serial dependence shows significant autocorrelation coefficients for indices. However, this is not the case for individual companies and Q(12) is significant for only 3 of the 20 stocks, suggesting that the independence hypothesis, generally, holds in the Pakistani market.

Ahmed and Rosser (1995) examine the existence of speculative bubbles in the Pakistani equity market, using daily indices. The authors use the Vector Autoregressive (VAR) technique to estimate a presumed fundamental on the stock market indices. Then they use the Hamilton regime-switching model and the associated Wald test to examine the presence of speculative trend, and they find the evidence of their presence. In order to examine the non-linear dynamics, the authors first test the series for ARCH effects and find the presence of these effects. After controlling for the ARCH effects, the authors apply the BDS test and find the evidence of such a non-linear structure. The non-linear dynamics, according to the authors, suggest that the Pakistani economy may be subject to instability and oscillation that may be generated by the erratic and complex dynamics of its stock market.

The above review shows that the studies on Pakistani equity market have so far been confined to the use of indices. However, as pointed out in the literature, e.g., Laurence (1986), the use of market index data may lead to a false perception of price change dependence even when price changes of individual shares represented by the index are independent, because the market index is affected by the stocks which are not traded frequently. The situation seems to be more serious in the case of emerging markets which are characterised by thin markets.

The only study, Jun and Uppal (1994), that examines company-level data uses the monthly prices of stocks. However, the monthly prices are more likely to reflect 
adjustment to new information than weekly or daily prices, and, thus, may show the market to be efficient.

Thus, there is a need to undertake a study that uses daily stock prices adjusted for dividends, rights issues, etc., for a large sample of stocks over a long observation period. The present paper aims to serve that purpose.

\section{Empirical Results of this Study}

\section{Serial Dependence}

The independence hypothesis was examined through the serial correlation test. Table 1 reports the serial correlation coefficients for the sample stocks and indices up to lag 20, along with the Ljung-Box Q-values at lag 5, 10, and 20. The table reveals that the market, in general, exhibits strong serial dependence. This is in contrast to the finding of Jun and Uppal (1994), who found the stock returns in the Pakistani market to be generally independent. However, they used monthly stock prices for their analysis. This suggests that the use of monthly stock prices may lead to a wrong conclusion.

Only one stock, LTVC, seems to be free of any serial dependence. Both the individual coefficients of LTVC at all lags and the Q-values show no signs of autocorrelation. Interestingly, it is the most active stock in the sample, where activity is represented by the trading volume.

The overwhelming majority of positive signs of the serial correlation coefficients indicates that the market, in general, adjusts slowly to new information. This is a common characteristic also observed in other markets, particularly in emerging markets. It can be observed that the serial dependence is much higher in sector indices than in individual stocks, where not only the significance of the coefficients continues to higher lags but also the magnitudes of the coefficients are higher than those of individual stocks. Among the stocks, the higher level of serial dependence is shown in ABBOTT, MILK, BATA, DAWOOD, etc. In fact, these stocks are among the least traded stocks included in the sample. This implies that the serial dependence is affected by the trading activity of stocks, and is likely to be more serious in inactive stocks.

It can also be seen from the table that most stocks exhibit significant coefficients at lower lags. For example, all stocks, except two, show significant coefficients at lag 1 , of which about two-thirds of the stocks have also significant coefficients at lag 2. For higher lags, the significance generally declines. Regarding the magnitude of the coefficients, it varies from a low of 0.003 for LTVC to a high of 0.390 for BROOK at lag 1 . Once again, the higher magnitudes are found in inactive stocks.

It would be useful to compare the results of the Pakistani market with those of the other markets. Such a comparison is shown in Table 2. The table compares the firstorder serial correlation coefficients found in various markets and provides information on the average as well as the number of positive and significant coefficients. The table 
Table 1

Serial Correlation Coefficients by Indices and Securities for the Sample Period (Jan. 1989 - Dec. 1993)

\begin{tabular}{|c|c|c|c|c|c|c|c|c|}
\hline & LAG 1 & LAG 2 & LAG 3 & LAG 4 & LAG 5 & LAG 6 & LAG 7 & LAG 8 \\
\hline GENERAL INDEX & $0.297 * *$ & $0.149 * *$ & $0.163^{* *}$ & $0.149 * *$ & $0.097 * *$ & 0.039 & $0.136^{* *}$ & $0.100 * *$ \\
\hline \multicolumn{9}{|l|}{ SECTOR INDICES } \\
\hline 1 TEXT & $0.241^{* *}$ & $0.114^{* *}$ & $0.106^{* *}$ & $0.101 * *$ & $0.106 * *$ & $0.093 * *$ & $0.091^{* *}$ & $0.120^{* *}$ \\
\hline 2 CHEM & $0.347 * *$ & $0.218 * *$ & $0.169 * *$ & $0.146^{* *}$ & $0.070 * *$ & 0.048 & 0.028 & 0.056 \\
\hline 3 SUGAR & $0.162 * *$ & $0.202 * *$ & $0.155^{* *}$ & $0.150 * *$ & $0.135^{* *}$ & $0.089 * *$ & $0.091 * *$ & $0.092 * *$ \\
\hline 4 PAPER & $0.193 * *$ & $0.115^{* *}$ & $0.078 *$ & 0.015 & -0.048 & $0.067 *$ & -0.024 & 0.032 \\
\hline 5 CEMENT & $0.223^{* *}$ & $0.196 * *$ & $0.141 * *$ & $0.128 * *$ & $0.090 * *$ & 0.028 & 0.045 & 0.040 \\
\hline 6 FUEL & $0.235 * *$ & $0.086 * *$ & $0.145 * *$ & $0.088 * *$ & 0.033 & 0.055 & $0.111^{* *}$ & 0.063 \\
\hline 7 TRANS & $0.086 * *$ & $0.060^{*}$ & -0.022 & -0.021 & 0.023 & $0.072 *$ & 0.055 & 0.024 \\
\hline 8 INSUR & $0.168 * *$ & $0.094 * *$ & $0.083^{* *}$ & 0.043 & $0.111^{* *}$ & 0.000 & 0.039 & 0.038 \\
\hline \multicolumn{9}{|l|}{ SECURITIES } \\
\hline 1 GRINDL & $0.101^{* *}$ & 0.038 & -0.020 & -0.006 & 0.001 & -0.044 & -0.031 & 0.015 \\
\hline 2 LTVC & 0.003 & -0.015 & -0.033 & -0.011 & -0.016 & -0.062 & -0.033 & 0.034 \\
\hline 3 NDLC & $0.063^{*}$ & $0.059 *$ & -0.018 & -0.015 & -0.048 & 0.031 & -0.033 & 0.032 \\
\hline 4 PICIC & $0.209 * *$ & $0.114^{* *}$ & 0.047 & -0.006 & 0.011 & -0.019 & 0.011 & -0.054 \\
\hline 5 ADAMJEE & $0.238 * *$ & 0.047 & 0.016 & 0.031 & $0.068 *$ & -0.001 & 0.008 & 0.027 \\
\hline 6 SHAHM & $0.193^{* *}$ & $0.077 *$ & $0.066^{*}$ & 0.037 & 0.020 & 0.027 & 0.005 & 0.023 \\
\hline 7 SHAKER & $0.158 * *$ & $0.147 * *$ & $0.088 * *$ & 0.052 & 0.016 & 0.039 & 0.045 & 0.054 \\
\hline 8 PAKLA & $0.212 * *$ & $0.085 * *$ & -0.038 & $-0.094 * *$ & $-0.065^{*}$ & -0.054 & -0.057 & -0.030 \\
\hline 9 PAKT & $0.090 * *$ & 0.040 & 0.017 & 0.015 & -0.007 & $-0.064 *$ & -0.033 & 0.050 \\
\hline $10 \mathrm{KESC}$ & $0.166^{* *}$ & 0.028 & $-0.086^{* *}$ & $-0.117^{* *}$ & -0.020 & -0.020 & 0.041 & 0.042 \\
\hline 11 NATR & $0.274 * *$ & $0.080 *$ & 0.012 & 0.006 & -0.001 & -0.031 & -0.005 & -0.019 \\
\hline $12 \mathrm{PSO}$ & $0.119 * *$ & $0.077 * *$ & $0.093 * *$ & 0.042 & 0.046 & 0.042 & -0.008 & 0.040 \\
\hline
\end{tabular}

Continued- 
Table 1-(Continued)

\begin{tabular}{|c|c|c|c|c|c|c|c|c|}
\hline 13 SUIN & $0.159 * *$ & -0.015 & -0.017 & -0.036 & 0.013 & 0.002 & 0.018 & 0.049 \\
\hline 14 SUIS & $0.258 * *$ & $0.102 * *$ & -0.014 & -0.018 & -0.013 & 0.006 & -0.003 & 0.017 \\
\hline 15 GENT & $0.158 * *$ & 0.034 & -0.046 & 0.042 & 0.021 & 0.017 & -0.003 & 0.005 \\
\hline 16 MILLT & $0.207 * *$ & $0.109 * *$ & -0.024 & -0.060 & -0.012 & -0.046 & -0.007 & -0.010 \\
\hline 17 PAKSU & $0.207 * *$ & 0.053 & 0.010 & -0.020 & -0.033 & -0.040 & -0.021 & -0.031 \\
\hline 18 PHILI & $0.125 * *$ & $0.094 * *$ & 0.029 & 0.023 & 0.012 & 0.004 & 0.013 & 0.000 \\
\hline 19 PNSC & $0.089 * *$ & -0.024 & -0.015 & -0.013 & 0.002 & 0.025 & 0.024 & -0.004 \\
\hline 20 АВВОТТ & $0.199 * *$ & $0.224 * *$ & $0.218^{* *}$ & $0.128 * *$ & $0.149 * *$ & $0.101^{* *}$ & 0.063 & $0.147^{* *}$ \\
\hline 21 DAWOOD & $0.232 * *$ & $0.119 * *$ & $0.137 * *$ & $0.069 *$ & 0.053 & $0.064 *$ & 0.021 & 0.029 \\
\hline 22 ENGRO & $0.275^{* *}$ & $0.178 * *$ & 0.053 & 0.053 & -0.036 & -0.048 & -0.053 & -0.003 \\
\hline 23 GLAXO & $0.294 * *$ & $0.190 * *$ & $0.131^{* *}$ & $0.139 * *$ & $0.092 * *$ & $0.091 * *$ & 0.036 & 0.035 \\
\hline 24 HOECHT & $0.192 * *$ & $0.112 * *$ & 0.028 & $0.064 *$ & 0.051 & -0.009 & -0.015 & 0.029 \\
\hline $25 \mathrm{ICI}$ & $0.106^{* *}$ & -0.025 & 0.040 & 0.040 & $-0.069 *$ & 0.009 & 0.033 & -0.051 \\
\hline 26 RECKI & $0.236 * *$ & $0.195 * *$ & $0.100^{* *}$ & 0.048 & -0.002 & -0.019 & 0.000 & -0.031 \\
\hline 27 WELLC & $0.208 * *$ & $0.117 * *$ & $0.071 *$ & 0.058 & -0.010 & 0.018 & -0.034 & 0.031 \\
\hline 28 WYTH & $0.293 * *$ & $0.231 * *$ & $0.158^{* *}$ & $0.098 * *$ & $0.130 * *$ & $0.106 * *$ & 0.026 & 0.050 \\
\hline 29 PACK & $0.200 * *$ & $0.165 * *$ & 0.051 & $0.094 * *$ & 0.013 & $0.068 *$ & -0.002 & -0.006 \\
\hline 30 BATA & $0.205^{* *}$ & $0.107 * *$ & $0.108^{* *}$ & $0.077 *$ & $0.084 * *$ & $0.067 *$ & 0.059 & 0.032 \\
\hline 31 BROOK & $0.390 * *$ & $0.271^{* *}$ & $0.102 * *$ & $0.117 * *$ & 0.061 & 0.048 & 0.062 & 0.069 \\
\hline 32 LEVER & $0.230 * *$ & 0.010 & -0.038 & 0.025 & -0.041 & -0.050 & -0.020 & 0.008 \\
\hline 33 MILK & $0.341 * *$ & $0.339 * *$ & $0.251^{* *}$ & $0.197 * *$ & $0.148^{* *}$ & $0.143^{* *}$ & 0.086* & 0.076 \\
\hline 34 RAFHAN & $0.193^{* *}$ & $0.122 * *$ & $0.095 * *$ & 0.059 & 0.061 & 0.038 & -0.022 & 0.028 \\
\hline 35 SHEZ & $0.161^{* *}$ & 0.061 & 0.051 & 0.023 & 0.010 & -0.012 & $-0.105^{* *}$ & -0.061 \\
\hline 36 BALOCH & 0.042 & 0.015 & $-0.080 * *$ & -0.013 & -0.008 & $-0.064 *$ & -0.017 & 0.024 \\
\hline
\end{tabular}

Continued- 
Table 1-(Continued)

\begin{tabular}{|c|c|c|c|c|c|c|c|c|}
\hline & LAG 9 & LAG 10 & LAG 13 & LAG 17 & LAG 20 & Lb (5) & LB (10) & LB (20) \\
\hline GENERAL INDEX & $0.079 *$ & $0.132 * *$ & $0.109 * *$ & $0.090 *$ & 0.057 & $196.00^{* *}$ & $259.00^{* *}$ & $341.00 * *$ \\
\hline \multicolumn{9}{|l|}{ SECTOR INDICES } \\
\hline $1 \mathrm{TEXT}$ & $0.110 * *$ & $0.109 * *$ & $0.110 * *$ & 0.060 & 0.043 & $121.00 * *$ & $185.00 * *$ & $235.00 * *$ \\
\hline 2 CHEM & 0.068 & 0.066 & $0.116^{* *}$ & 0.043 & 0.032 & $259.00 * *$ & $277.00 * *$ & $331.00 * *$ \\
\hline 3 SUGAR & $0.088 * *$ & 0.046 & 0.025 & 0.027 & -0.005 & $153.00 * *$ & $194.00 * *$ & $221.00 * *$ \\
\hline 4 PAPER & 0.050 & 0.049 & $0.073^{*}$ & -0.010 & 0.013 & $68.60^{* *}$ & $81.50 * *$ & $126.00^{* *}$ \\
\hline 5 CEMENT & 0.035 & -0.005 & 0.021 & $0.081 *$ & 0.018 & $155.00 * *$ & $161.00 * *$ & $193.00 * *$ \\
\hline 6 FUEL & $0.071 * *$ & 0.063 & 0.056 & 0.033 & 0.034 & $108.00 * *$ & $141.00 * *$ & $164.00 * *$ \\
\hline 7 TRANS & 0.004 & -0.033 & $0.068 *$ & 0.037 & 0.054 & $14.50 *$ & $26.10^{* *}$ & $50.10^{* *}$ \\
\hline 8 INSUR & 0.036 & $0.088 * *$ & 0.042 & $0.099 * *$ & $0.065^{*}$ & $67.80 * *$ & $81.80 * *$ & $122.00^{* *}$ \\
\hline \multicolumn{9}{|l|}{ SECURITIES } \\
\hline 1 GRINDL & -0.021 & 0.031 & $0.061^{*}$ & 0.032 & 0.005 & $14.20^{*}$ & $19.50 *$ & $34.20^{*}$ \\
\hline 2 LTVC & 0.040 & 0.016 & -0.002 & 0.056 & -0.061 & 1.73 & 9.86 & 23.30 \\
\hline 3 NDLC & 0.041 & 0.037 & 0.011 & -0.039 & 0.029 & $12.00 *$ & $19.20^{*}$ & 24.10 \\
\hline 4 PICIC & 0.009 & 0.033 & -0.034 & 0.029 & 0.044 & $69.10 * *$ & $74.40 * *$ & $82.10 * *$ \\
\hline 5 ADAMJEE & 0.034 & $0.073^{*}$ & -0.011 & 0.014 & -0.007 & $76.10^{* *}$ & $84.70 * *$ & $96.40 * *$ \\
\hline 6 SHAHM & -0.044 & 0.008 & 0.051 & -0.022 & -0.041 & $57.60 * *$ & $61.50 * *$ & $81.50 * *$ \\
\hline 7 SHAKER & 0.005 & 0.029 & 0.012 & 0.078* & -0.024 & $67.10^{* *}$ & $75.80 * *$ & $94.60 * *$ \\
\hline 8 PAKLA & -0.055 & -0.038 & -0.023 & $0.111 * *$ & -0.041 & $70.90 * *$ & $83.20 * *$ & $159.00 * *$ \\
\hline 9 PAKT & 0.003 & 0.017 & -0.039 & $0.078 * *$ & 0.023 & $12.00 *$ & $21.30 * *$ & $46.80 * *$ \\
\hline $10 \mathrm{KESC}$ & 0.035 & 0.026 & 0.020 & 0.057 & 0.027 & $58.20 * *$ & $65.00 * *$ & $81.30 * *$ \\
\hline 11 NATR & 0.020 & $0.072 *$ & 0.001 & 0.042 & 0.040 & $95.70^{* *}$ & $104.00 * *$ & $114.00^{* *}$ \\
\hline 12 PSO & -0.013 & -0.043 & $0.069 *$ & $0.066^{*}$ & 0.030 & $38.10 * *$ & $44.50 * *$ & $90.30 * *$ \\
\hline 13 SUIN & -0.012 & 0.045 & 0.057 & $-0.063 *$ & 0.040 & $31.90 * *$ & $37.70 * *$ & $59.80 * *$ \\
\hline 14 SUIS & -0.020 & -0.046 & -0.048 & 0.017 & -0.050 & $91.20 * *$ & $94.50 * *$ & $112.00 * *$ \\
\hline
\end{tabular}


Table $1-$ (Continued)

\begin{tabular}{|c|c|c|c|c|c|c|c|c|}
\hline 15 GENT & -0.033 & 0.020 & -0.023 & 0.053 & -0.045 & $35.60 * *$ & $37.70 * *$ & $50.30 * *$ \\
\hline 16 MILLT & 0.040 & 0.022 & -0.024 & -0.022 & -0.041 & $69.30 * *$ & $74.40^{* *}$ & $91.50 * *$ \\
\hline 17 PAKSU & 0.023 & 0.050 & 0.034 & -0.003 & -0.001 & $55.20 * *$ & $62.30 * *$ & $74.40 * *$ \\
\hline 18 PHILI & 0.045 & 0.034 & -0.010 & 0.002 & 0.003 & $30.20 * *$ & $34.30 * *$ & $62.50 * *$ \\
\hline 19 PNSC & $-0.070^{*}$ & -0.021 & 0.002 & 0.057 & 0.007 & 10.30 & 18.10 & 29.60 \\
\hline 20 ABВОTТ & $0.089 *$ & $0.079 *$ & $0.070^{*}$ & 0.013 & 0.017 & $207.00 * *$ & $266.00 * *$ & $305.00 * *$ \\
\hline 21 DAWOOD & 0.033 & 0.006 & -0.000 & -0.051 & 0.000 & $111.00^{* *}$ & $118.00^{* *}$ & $134.00 * *$ \\
\hline 22 ENGRO & -0.044 & -0.023 & -0.014 & 0.056 & $0.068^{*}$ & $134.00 * *$ & $143.00 * *$ & $166.00 * *$ \\
\hline 23 GLAXO & 0.023 & 0.000 & -0.000 & 0.009 & -0.007 & $197.00 * *$ & $210.00 * *$ & $211.00 * *$ \\
\hline 24 HOEСНТ & 0.042 & 0.054 & $0.065^{*}$ & -0.010 & 0.027 & $66.50 * *$ & $73.40 * *$ & $82.40 * *$ \\
\hline 25 ICI & 0.027 & $0.074^{*}$ & $0.086^{* *}$ & -0.009 & 0.051 & $23.10^{* *}$ & $34.90 * *$ & $68.50 * *$ \\
\hline 26 RECKI & -0.037 & -0.002 & $-0.076^{*}$ & -0.011 & 0.055 & $124.00 * *$ & $128.00 * *$ & $143.00 * *$ \\
\hline 27 WELLC & $0.066^{*}$ & -0.003 & 0.007 & 0.015 & $0.081^{* *}$ & $77.00 * *$ & $84.90 * *$ & $104.00 * *$ \\
\hline 28 WYTH & 0.020 & 0.014 & 0.024 & 0.052 & $0.081^{*}$ & $224.00 * *$ & $241.00 * *$ & $262.00 * *$ \\
\hline 29 PACK & -0.038 & 0.020 & 0.004 & -0.045 & $0.065^{*}$ & $92.20 * *$ & $99.90 * *$ & $113.00^{* *}$ \\
\hline 30 BATA & 0.019 & 0.038 & 0.033 & 0.056 & 0.045 & $91.70 * *$ & $105.00 * *$ & $120.00 * *$ \\
\hline 31 BROOK & $0.078^{*}$ & 0.014 & 0.061 & 0.004 & -0.023 & $297.00 * *$ & $317.00 * *$ & $331.00 * *$ \\
\hline 32 LEVER & 0.052 & 0.033 & 0.001 & -0.024 & -0.001 & $66.30 * *$ & $74.20 * *$ & $89.60 * *$ \\
\hline 33 MILK & 0.024 & -0.018 & -0.025 & -0.031 & -0.072 & $416.00 * *$ & $457.00 * *$ & $473.00 * *$ \\
\hline 34 RAFHAN & 0.049 & 0.003 & 0.045 & -0.043 & -0.013 & $80.30 * *$ & $86.40 * *$ & $97.70^{* *}$ \\
\hline 35 SHEZ & -0.042 & -0.003 & -0.026 & $0.065 *$ & 0.015 & $34.10 * *$ & $51.60 * *$ & $72.10 * *$ \\
\hline 36 BALOCH & 0.038 & -0.022 & -0.021 & 0.002 & -0.017 & 10.20 & 18.30 & 20.60 \\
\hline
\end{tabular}

Note: $\mathrm{LB}(\mathrm{k})$ is the Ljung Box $\mathrm{Q}$ statistic at lag $\mathrm{k},{ }^{* *}$ and $*$ indicate significance level at 1 percent and 5 percent respectively. 
Table 2

Serial Correlation Coefficients Reported for Various Markets

\begin{tabular}{|c|c|c|c|c|c|}
\hline Study & Country/ies & $\begin{array}{l}\text { No. of } \\
\text { Stocks }\end{array}$ & $\begin{array}{c}\text { Average } \\
\text { Coeff. }\end{array}$ & $\begin{array}{l}\text { Positive } \\
\text { Terms }\end{array}$ & $\begin{array}{l}\text { Coeff. } \\
>2 \text { SD }\end{array}$ \\
\hline Fama (1965) & USA & 30 & 0.026 & $22(73)$ & $11(37)$ \\
\hline \multirow[t]{8}{*}{ Solnik (1973) } & France & 65 & -0.019 & $33(51)$ & $41(63)$ \\
\hline & Italy & 30 & -0.023 & $14(47)$ & $9(30)$ \\
\hline & UK & 40 & 0.072 & $34(85)$ & $21(53)$ \\
\hline & Germany & 35 & 0.078 & $28(80)$ & $23(66)$ \\
\hline & Netherlands & 24 & 0.031 & $17(71)$ & $9(38)$ \\
\hline & Belgium & 17 & -0.018 & $7(41)$ & $5(29)$ \\
\hline & Switzerland & 17 & 0.012 & $11(65)$ & $4(24)$ \\
\hline & Sweden & 6 & 0.056 & $3(50)$ & $1(17)$ \\
\hline \multicolumn{6}{|l|}{ Conrad and } \\
\hline Juttner (1973) & Germany & 54 & -0.142 & $25(46)$ & $39(72)$ \\
\hline \multirow{2}{*}{$\begin{array}{l}\text { Jennergren and } \\
\text { Korsvold (1975) }\end{array}$} & Norway & 15 & 0.068 & $13(87)$ & $8(53)$ \\
\hline & Sweden & 30 & 0.098 & 29(97) & $26(87)$ \\
\hline \multirow[t]{2}{*}{ Laurence (1986) } & Malaysia & 16 & 0.039 & $13(81)$ & $5(31)$ \\
\hline & Singapore & 24 & 0.057 & $17(71)$ & $19(79)$ \\
\hline \multirow{2}{*}{$\begin{array}{l}\text { Butler and Malaikah } \\
\text { (1992) }\end{array}$} & Kuwait & 36 & 0.053 & $25(69)$ & $13(36)$ \\
\hline & Saudi Arabia & 35 & -0.471 & $0(00)$ & $35(100)$ \\
\hline Aybar (1992) & Turkey & 41 & 0.138 & NA & $38(93)$ \\
\hline Present Study & Pakistan & 36 & 0.190 & $36(100)$ & $34(94)$ \\
\hline
\end{tabular}

also reports the number of stocks used in these studies. The terms in the parenthesis show the percentages of corresponding stocks in total stocks, e.g., in the study by Fama for the US market, 22 of 30 stocks (i.e., 73 percent) had positive signs and 11 of 30 stocks (i.e., 37 percent) had significant coefficients.

It can be seen from Table 2 that Pakistani market has the highest magnitude of average coefficient after Saudi Arabia, which has an unusually high magnitude. The significance of the coefficients varies across the markets. Although a high proportion of significant coefficients are shown in emerging markets like Pakistan, Saudi Arabia, and Turkey, yet some of the developed markets like Sweden, Singapore, and Germany also show a considerable level of significance. Regarding the signs, it seems that the equity markets, in general, exhibit positive coefficients indicating slow adjustment to new information. 


\section{Distribution of Stock Returns}

To examine the distribution of stock returns, frequency distributions for all stocks and indices were constructed and are shown in Table 3. The table shows the cumulative proportion of returns within a given (x) Standard Deviation (SD) from the mean return, where $\mathrm{x}$ ranges from 0.5 to 5.0. The last column shows the proportion of returns beyond " 5 SD" from mean return. The proportions for the normal distribution are also given in the first row for comparison.

It can be seen from the table that the proportions for all stocks and indices are much greater than those of the normal in the intervals, which are closer to the mean indicating higher peaks. Similarly, the proportions are higher in the interval of beyond “5 SD”, implying longer tails.

The finding of higher peaks and longer tails in the distribution of stock returns in this paper is in line with the empirical evidence from other markets. Table 4 compares the distribution of stock returns in the Pakistani equity market with those observed in other equity markets by other authors. The table provides the empirical distributions along with the normal distribution. These distributions represent the average distribution of stocks in the corresponding market. It can be noted that although all markets have high-peaked and long-tailed distributions, the extent of the peaks and tails differs across the markets. The distributions in the emerging markets have higher peaks and longer tails than those in developed markets. This suggests that market thinness (infrequent trading) may be an important factor in the departure of observed distributions from normality.

\section{SUMMARY AND CONCLUSIONS}

The objective of the paper was to examine the Random Walk model in the Pakistani equity market. The model was tested using daily data for 36 individual stocks, 8 sector indices, and the general market index from January 1, 1989 to December 30, 1993.

The distributional aspect was tested through frequency distributions which shows that stock returns in the Pakistani market, as in other markets, cannot be characterised by the normal distribution. Hence, theoretical models must be used with caution. The analysis indicates that the degree of departure of observed distributions from the normal are higher in emerging markets, which are thin markets, suggesting that market thinness is one of the factors which caused the observed distributions to depart from the normal.

The independence hypothesis was tested through the serial correlation test. The results indicate the presence of strong serial dependence in stock returns, suggesting that the random walk model is not appropriate to describe the stock return behaviour in the Pakistani market. The extent of serial dependence, however, differs between sector indices and individual stocks, where the indices show a much higher serial dependence, suggesting that using index data to examine serial dependence may not be appropriate. 
Table 3

Frequency Distributions of Returns by Indices and Securities for the Sample Period (Jan. 1989 - Dec. 1993).

\begin{tabular}{|c|c|c|c|c|c|c|c|c|c|}
\hline & $0.5 \mathrm{SD}$ & $1.0 \mathrm{SD}$ & $1.5 \mathrm{SD}$ & $2.0 \mathrm{SD}$ & $2.5 \mathrm{SD}$ & $3.0 \mathrm{SD}$ & 4.0 SD & $5.0 \mathrm{SD}$ & $>5.0 \mathrm{SD}$ \\
\hline NORMAL DIST. & 0.3830 & 0.6826 & 0.8664 & 0.9545 & 0.9876 & 0.9973 & 0.9999 & 0.9999 & 0.0000006 \\
\hline GENERAL INDEX & 0.5674 & 0.8048 & 0.8990 & 0.9421 & 0.9629 & 0.9784 & 0.9940 & 0.9983 & 0.0017300 \\
\hline \multicolumn{10}{|l|}{ SECTOR INDICES } \\
\hline 1 TEXT & 0.5812 & 0.8126 & 0.9050 & 0.9482 & 0.9715 & 0.9810 & 0.9914 & 0.9966 & 0.0034500 \\
\hline 2 CHEM & 0.5199 & 0.7841 & 0.9007 & 0.9430 & 0.9698 & 0.9827 & 0.9957 & 0.9966 & 0.0034500 \\
\hline 3 SUGAR & 0.5570 & 0.8230 & 0.9136 & 0.9525 & 0.9767 & 0.9853 & 0.9905 & 0.9957 & 0.0043200 \\
\hline 4 PAPER & 0.5777 & 0.8066 & 0.9145 & 0.9499 & 0.9689 & 0.9819 & 0.9905 & 0.9966 & 0.0034500 \\
\hline 5 CEMENT & 0.6054 & 0.8463 & 0.9162 & 0.9447 & 0.9629 & 0.9758 & 0.9888 & 0.9974 & 0.0025900 \\
\hline 6 FUEL & 0.6054 & 0.8135 & 0.8990 & 0.9413 & 0.9620 & 0.9758 & 0.9914 & 0.9966 & 0.0034500 \\
\hline 7 TRANS & 0.6114 & 0.8238 & 0.9128 & 0.9551 & 0.9715 & 0.9801 & 0.9896 & 0.9948 & 0.0051800 \\
\hline 8 INSUR & 0.5682 & 0.7833 & 0.8912 & 0.9413 & 0.9681 & 0.9801 & 0.9948 & 0.9983 & 0.0017300 \\
\hline AVERAGE & 0.5783 & 0.8116 & 0.9066 & 0.9470 & 0.9689 & 0.9804 & 0.9916 & 0.9965 & 0.0034525 \\
\hline \multicolumn{10}{|l|}{ SECURITIES } \\
\hline 1 GRINDL & 0.5355 & 0.7707 & 0.8811 & 0.9453 & 0.9743 & 0.9846 & 0.9949 & 0.9983 & 0.0017100 \\
\hline 2 LTVC & 0.5102 & 0.7483 & 0.8702 & 0.9405 & 0.9766 & 0.9883 & 0.9981 & 1.0000 & 0.0000000 \\
\hline 3 NDLC & 0.5774 & 0.7930 & 0.9059 & 0.9521 & 0.9735 & 0.9820 & 0.9889 & 0.9957 & 0.0042800 \\
\hline 4 PICIC & 0.5757 & 0.7998 & 0.8905 & 0.9307 & 0.9589 & 0.9761 & 0.9957 & 0.9991 & 0.0008600 \\
\hline 5 ADAMJEE & 0.5620 & 0.8041 & 0.9033 & 0.9333 & 0.9641 & 0.9769 & 0.9940 & 0.9983 & 0.0017100 \\
\hline 6 SHAHM & 0.5988 & 0.7973 & 0.8999 & 0.9410 & 0.9649 & 0.9786 & 0.9915 & 0.9974 & 0.0025700 \\
\hline 7 SHAKER & 0.6741 & 0.8144 & 0.8854 & 0.9470 & 0.9666 & 0.9761 & 0.9872 & 0.9983 & 0.0017100 \\
\hline 8 PAKLA & 0.5894 & 0.7975 & 0.8808 & 0.9395 & 0.9650 & 0.9792 & 0.9934 & 0.9972 & 0.0028400 \\
\hline 9 РАКТ & 0.6767 & 0.8341 & 0.9085 & 0.9495 & 0.9666 & 0.9769 & 0.9880 & 0.9940 & 0.0059900 \\
\hline
\end{tabular}


Table 3-(Continued)

\begin{tabular}{|c|c|c|c|c|c|c|c|c|c|}
\hline $10 \mathrm{KESC}$ & 0.6074 & 0.8092 & 0.8999 & 0.9367 & 0.9598 & 0.9778 & 0.9889 & 0.9983 & 0.0017100 \\
\hline 11 NATR & 0.5680 & 0.8041 & 0.8948 & 0.9444 & 0.9692 & 0.9786 & 0.9915 & 0.9974 & 0.0025700 \\
\hline 12 PSO & 0.6074 & 0.8169 & 0.8982 & 0.9461 & 0.9701 & 0.9872 & 0.9932 & 0.9966 & 0.0034200 \\
\hline 13 SUIN & 0.6108 & 0.8015 & 0.8905 & 0.9393 & 0.9641 & 0.9743 & 0.9915 & 0.9991 & 0.0008600 \\
\hline 14 SUIS & 0.6501 & 0.8358 & 0.9076 & 0.9376 & 0.9572 & 0.9752 & 0.9906 & 0.9949 & 0.0051300 \\
\hline 15 GENT & 0.5612 & 0.7904 & 0.8879 & 0.9358 & 0.9615 & 0.9812 & 0.9915 & 0.9991 & 0.0008600 \\
\hline 16 MILLT & 0.6168 & 0.8494 & 0.9196 & 0.9581 & 0.9718 & 0.9786 & 0.9897 & 0.9932 & 0.0068400 \\
\hline 17 PAKS & 0.6373 & 0.8375 & 0.9068 & 0.9470 & 0.9649 & 0.9786 & 0.9915 & 0.9949 & 0.0051300 \\
\hline 18 PHILI & 0.6382 & 0.8118 & 0.9042 & 0.9358 & 0.9624 & 0.9786 & 0.9897 & 0.9949 & 0.0051300 \\
\hline 19 PNSC & 0.5295 & 0.7844 & 0.8905 & 0.9393 & 0.9675 & 0.9812 & 0.9940 & 0.9991 & 0.0008600 \\
\hline 20 АВВОТТ & 0.7305 & 0.8708 & 0.9239 & 0.9504 & 0.9641 & 0.9752 & 0.9889 & 0.9949 & 0.0051300 \\
\hline 21 DAWOOD & 0.6997 & 0.8743 & 0.9316 & 0.9521 & 0.9658 & 0.9743 & 0.9863 & 0.9923 & 0.0077000 \\
\hline 22 ENGRO & 0.6057 & 0.8152 & 0.8879 & 0.9401 & 0.9641 & 0.9778 & 0.9915 & 0.9974 & 0.0025700 \\
\hline 23 GLAXO & 0.5808 & 0.8298 & 0.9051 & 0.9453 & 0.9641 & 0.9743 & 0.9880 & 0.9974 & 0.0025700 \\
\hline 24 HOECHT & 0.6057 & 0.8041 & 0.8897 & 0.9350 & 0.9598 & 0.9761 & 0.9932 & 0.9983 & 0.0017100 \\
\hline 25 ICI & 0.5997 & 0.8264 & 0.8991 & 0.9333 & 0.9538 & 0.9743 & 0.9923 & 0.9991 & 0.0008600 \\
\hline 26 RECKI & 0.5535 & 0.7819 & 0.8871 & 0.9376 & 0.9649 & 0.9812 & 0.9923 & 0.9983 & 0.0017100 \\
\hline 27 WELLC & 0.6193 & 0.8144 & 0.8991 & 0.9435 & 0.9666 & 0.9778 & 0.9906 & 0.9966 & 0.0034200 \\
\hline 28 WYTH & 0.6595 & 0.8366 & 0.9033 & 0.9393 & 0.9581 & 0.9666 & 0.9897 & 0.9974 & 0.0025700 \\
\hline 29 PACK & 0.5988 & 0.8289 & 0.9025 & 0.9307 & 0.9624 & 0.9735 & 0.9915 & 0.9983 & 0.0017100 \\
\hline 30 BATA & 0.5997 & 0.8007 & 0.9102 & 0.9410 & 0.9589 & 0.9735 & 0.9889 & 0.9991 & 0.0008600 \\
\hline 31 BROOK & 0.5697 & 0.7998 & 0.8897 & 0.9333 & 0.9649 & 0.9743 & 0.9957 & 1.0000 & 0.0000000 \\
\hline 32 LEVER & 0.5945 & 0.8144 & 0.9016 & 0.9427 & 0.9598 & 0.9701 & 0.9923 & 0.9983 & 0.0017100 \\
\hline 33 MILK & 0.7006 & 0.8221 & 0.8888 & 0.9316 & 0.9521 & 0.9675 & 0.9932 & 0.9974 & 0.0025700 \\
\hline 34 RAFHAN & 0.6074 & 0.8024 & 0.9033 & 0.9358 & 0.9632 & 0.9752 & 0.9940 & 0.9974 & 0.0025700 \\
\hline 35 SHEZ & 0.5372 & 0.7816 & 0.8763 & 0.9401 & 0.9662 & 0.9845 & 0.9952 & 1.0000 & 0.0000000 \\
\hline 36 BALOCH & 0.5004 & 0.7639 & 0.8871 & 0.9470 & 0.9666 & 0.9820 & 0.9957 & 0.9991 & 0.0008600 \\
\hline AVERAGE & 0.6025 & 0.8102 & 0.8975 & 0.9410 & 0.9643 & 0.9774 & 0.9917 & 0.9974 & 0.0025750 \\
\hline
\end{tabular}


Table 4

Average Frequency Distribution of Stock Returns Observed in Various Markets

\begin{tabular}{llllllllcc}
\hline & $0.5 \mathrm{SD}$ & $1.0 \mathrm{SD}$ & $1.5 \mathrm{SD}$ & $2.0 \mathrm{SD}$ & $2.5 \mathrm{SD}$ & $3.0 \mathrm{SD}$ & 4.0 SD & $5.0 \mathrm{SD}$ & $>5.0 \mathrm{SD}$ \\
\hline NORMAL DIST. & 0.3830 & 0.6826 & 0.8664 & 0.9545 & 0.9876 & 0.9973 & 0.9999 & 0.9999 & 0.0000006 \\
USA & 0.4667 & 0.7469 & 0.8847 & 0.9478 & 0.9756 & 0.9886 & 0.9970 & 0.9988 & 0.0012 \\
NORWAY & 0.5534 & 0.8038 & 0.8895 & 0.9447 & 0.9681 & 0.9815 & 0.9921 & 0.9963 & 0.0037 \\
SWEDEN (ACTIVE) & 0.4624 & 0.7487 & 0.8833 & 0.9451 & 0.9750 & 0.9877 & 0.9966 & 0.9990 & 0.0010 \\
SWEDEN (INACTIVE) & 0.5332 & 0.7685 & 0.8870 & 0.9460 & 0.9739 & 0.9845 & 0.9955 & 0.9980 & 0.0020 \\
MALAYSIA & 0.5609 & 0.7967 & 0.8895 & 0.9462 & & 0.9833 & 0.9943 & 0.9970 & 0.0030 \\
SINGAPORE & 0.5814 & 0.8085 & 0.9056 & 0.9487 & & 0.9820 & 0.9926 & 0.9963 & 0.0037 \\
SAUDI ARABIA & 0.5035 & 0.7662 & 0.8860 & 0.9440 & 0.9712 & 0.9852 & 0.9955 & 0.9983 & 0.0017 \\
KUWAIT & 0.5516 & 0.8257 & 0.9125 & 0.9518 & 0.9726 & 0.9823 & 0.9916 & 0.9952 & 0.0048 \\
PAKISTAN & 0.6025 & 0.8102 & 0.8976 & 0.9410 & 0.9643 & 0.9775 & 0.9917 & 0.9974 & 0.0026 \\
\hline Sources: For USA, Fama (1965); Norway and Sweden, Jennergren and Korvold (1975); Malaysia and Singapore, Laurence (1986); Saudi Arabia and Kuwait,
\end{tabular}
Malaikah (1990). 
The results also contradict the study by Jun and Uppal (1994), who used monthly stock prices and found support for the independence hypothesis, indicating that the use of monthly data may lead to a wrong conclusion regarding the efficiency of the market.

The results regarding serial dependence, however, must be seen with care. Since stock returns are not normally distributed, the calculated standard deviations of these returns underestimate the actual standard deviations. This causes the $t$-values to be overestimated. As a result, some of the insignificant coefficients may turn significant. It can be inferred, then, that one of the reasons for observing higher serial dependence in emerging markets is the higher degree of departure from normal distributions in these markets.

The analysis also indicates that the Pakistani market, like other emerging markets, adjusts slowly to new information, thus pointing to the weaknesses of the market regarding the dissemination of relevant information to potential investors. This suggests that effective measures should be taken to develop systems which facilitate dissemination of pertinent information. Strict rules should be set to release timely and relevant information. It may also be kept in view that even when the information is available, it will not be effective until a thorough financial analysis of the available information is made the basis for advising investors, rather than having to rely on informal tips or intuition. An effective measure in this regard may be the setting up of an equity market research centre and data bases where the pertinent information could be easily and quickly accessible to the public.

\section{REFERENCES}

Ahmed, E., and J. B. Rosser (1995) Non-linear Speculative Bubbles in the Pakistani Stock Market. The Pakistan Development Review 34:1 25-41.

Aybar, C. B. (1992) Descriptive Analysis of Stock Returns Behaviour in an Emerging Equity Market: The Case of Turkey. Unpublished Ph.D. diss., Ohio State University, USA.

Conrad, K., and D. Juttner (1973) Recent Behaviour of Stock Market Prices in Germany and the Random Walk Hypothesis. Kyklos 26: 576-599.

Dryden, M. (1970) A Statistical Study of UK Share Prices. Scottish Journal of Political Economy 17: 369-389.

Errunza, V., and E. Losq (1985) The Behaviour of Stock Prices on LDC Markets. Journal of Banking and Finance 9: 561-575.

Fama, E. (1965) The Behaviour of Stock Market Prices. Journal of Business 38: 34105.

Granger, M., and O. Morgenstern (1963) Spectral Analysis of New York Stock Market Prices. Kyklos 16: 1-27

Jennergren, L., and P. Korsvold (1975) The Non-random Character of Norwegian and Swedish Stock Market Prices. In E. J. Elton and M. J. Gruber (eds) International 
Capital Markets. Amsterdam: North-Holland : 37-54.

Jun, K., and Jamshed Uppal (1994) Portfolio Flows to Pakistan: Trends and Policies. A paper presented at the Private Sector Development Conference, Lahore University of Management Sciences, Lahore.

Kendall, M. (1953) The Analysis of Economic Time Series. Part I. Prices. Journal of the Royal Statistical Society 96: 11-25.

Khilji, N. (1993) The Behaviour of Stock Returns in an Emerging Market: A Case Study of Pakistan. The Pakistan Development Review 32:4 593-604.

Khilji, N. (1994) Non-linear Dynamics and Chaos: Application to Financial Markets in Pakistan. The Pakistan Development Review 33:4 1417-1429.

Laurence, M. (1986) Weak Form Efficiency in the Kuala Lumpur and Singapore Stock Markets. Journal of Banking and Finance 10: 431-445.

Malaikah, S. J. (1990) Saudi Arabia and Kuwait: A Study of Stock Market Behaviour and Its Policy Implications. Unpublished Ph.D. diss., Michigan State University, USA.

Mandelbrot, B. (1963) The Variation of Certain Speculative Prices. Journal of Business 36: 394-419.

Solnik, B. (1973) Note on the Validity of the Random Walk for European Stock Prices. Journal of Finance 28: 1151-1159.

Uppal, J. (1993) The Internationalisation of the Pakistani Stock Market: An Empirical Investigation. The Pakistan Development Review 32:4 605-618. 